\title{
SINTESIS DAN KARAKTERISASI KOMPOSIT SMART MAGNETIC BERBASIS BROWNMILLERITE $\mathrm{Ca}_{2} \mathrm{Fe}_{2} \mathrm{O}_{5} / \mathrm{NiFe}_{2} \mathrm{O}_{4}$
}

\author{
Tria Madesa, Sari Hasnah Dewi, Wisnu Ari Adi \\ Pusat Sains dan Teknologi Bahan Maju, Kawasan Puspiptek Serpong, \\ Tangerang Selatan 15314, Indonesia \\ madesa@batan.go.id, hasyari@batan.go.id,dan dwisnuaa@batan.go.id
}

\begin{abstract}
ABSTRAK
SINTESIS DAN KARAKTERISASI KOMPOSIT SMART MAGNETIC BERBASIS BROWNMILLERITE $\mathrm{Ca}_{2} \mathrm{Fe}_{2} \mathrm{O}_{5} / \mathrm{NiFe}_{2} \mathrm{O}_{4}$. Komposit smart magnetic $\mathrm{Ca}_{2} \mathrm{Fe}_{2} \mathrm{O}_{5} / \mathrm{NiFe}_{2} \mathrm{O}_{4}$ disintesis dengan metode reaksi padatan menggunakan high energy milling. Komposit $\mathrm{Ca}_{2} \mathrm{Fe}_{2} \mathrm{O}_{5} / \mathrm{NiFe}_{2} \mathrm{O}_{4}$ dibuat dari percampuran serbuk oksida $\mathrm{CaCO}_{3}, \mathrm{NiO}$, dan $\mathrm{Fe}_{2} \mathrm{O}_{3}$. Campuran di-milling selama 5 jam dan kemudian disinter pada $1000^{\circ} \mathrm{C}$ selama 5 jam. Analisis fasa sampel diukur dengan menggunakan X-ray difraktometer (XRD) dan dianalisis menggunakan metode Rietveld. Hasil refinement menunjukkan bahwa sampel merupakan komposit $\mathrm{Ca}_{2} \mathrm{Fe}_{2} \mathrm{O}_{5} / \mathrm{NiFe}_{2} \mathrm{O}_{4}$ dengan fraksi massa antara keduanya berturut-turut adalah $57,14 \%$ dan $39,27 \%$, yang juga didukung dari hasil morfologi permukaan menunjukkan sampel terdiri dari dua bentuk partikel yang berbeda. Berdasarkan hasil analisis sifat magnetik, sampel komposit $\mathrm{Ca}_{2} \mathrm{Fe}_{2} \mathrm{O}_{5} / \mathrm{NiFe}_{2} \mathrm{O}_{4}$ bersifat feromagnetik. Disimpulkan bahwa telah berhasil dibuat sampel komposit $\mathrm{Ca}_{2} \mathrm{Fe}_{2} \mathrm{O}_{5} / \mathrm{NiFe}_{2} \mathrm{O}_{4}$.
\end{abstract}

Kata kunci : komposit, $\mathrm{Ca}_{2} \mathrm{Fe}_{2} \mathrm{O}_{5}, \mathrm{NiFe}_{2} \mathrm{O}_{4}$, analisis fasa, morfologi, sifat magnetik

\begin{abstract}
Smart composite magnetic $\mathrm{Ca}_{2} \mathrm{Fe}_{2} \mathrm{O}_{5} / \mathrm{NiFe}_{2} \mathrm{O}_{4}$ has been synthesized by solid state reaction method using high energy milling. $\mathrm{Ca}_{2} \mathrm{Fe}_{2} \mathrm{O}_{5} / \mathrm{NiFe}_{2} \mathrm{O}_{4}$ composite was made from a mixture of oxide powders, namely $\mathrm{CaCO}_{3}$, $\mathrm{NiO}$, and $\mathrm{Fe}_{2} \mathrm{O}_{3}$. Mixture was milled for 5 hours and then sintered at $1000^{\circ} \mathrm{C}$ for 5 hours. Phase analysis of the samples was measured using X-ray diffractometer (XRD) and analyzed using the Rietveld method. Refinement results indicate that the sample is a composite $\mathrm{Ca}_{2} \mathrm{Fe}_{2} \mathrm{O}_{5} / \mathrm{NiFe}_{2} \mathrm{O}_{4}$ a mass fraction between $\mathrm{Ca}_{2} \mathrm{Fe}_{2} \mathrm{O}_{5}$ and $\mathrm{NiFe}_{2} \mathrm{O}_{4}$ are respectively $57.14 \%$ and $39.27 \%$, which is also supported by the results of the surface morphology shows a sample consisting of two of different particle shapes. Based on the analysis of magnetic properties of composite samples $\mathrm{Ca}_{2} \mathrm{Fe}_{2} \mathrm{O}_{5} / \mathrm{NiFe}_{2} \mathrm{O}_{4}$ is ferromagnetic. It was concluded that it has successfully made a composite sample $\mathrm{Ca}_{2} \mathrm{Fe}_{2} \mathrm{O}_{5} / \mathrm{NiFe}_{2} \mathrm{O}_{4}$.
\end{abstract}

Keywords: composite, $\mathrm{Ca}_{2} \mathrm{Fe}_{2} \mathrm{O}_{5}, \mathrm{NiFe}_{2} \mathrm{O}_{4}$, phase analysis, morphology, magnetic properties 


\section{PENDAHULUAN}

Brownmillerite dengan senyawa empiris: $\mathrm{A}_{2} \mathrm{~B}(\mathrm{MT}) \mathrm{O}_{5}$ adalah jenis perovskite kekurangan oksigen (A: $\mathrm{Ca}, \mathrm{Ba}, \mathrm{Sr}$; $\mathrm{B}$ : Fe; dan MT: Mn, Ni, Co). $\mathrm{Ca}_{2} \mathrm{Fe}_{2} \mathrm{O}_{5}$ merupakan salah satu senyawa brownmillerite. Mineral brownmillerite yang ada di alam adalah komposisi $\mathrm{Ca}_{2} \mathrm{AlFeO}_{5}$ yang mengkristal dengan grup ruang $\mathrm{I} \quad 2 \mathrm{~m} \quad \mathrm{~b}$ (sistem kristal ortorombik) $[1,2]$.

Banyak studi tentang pemanfaatan senyawa brownmillerite telah diteliti dan dilakukan. Senyawa $\mathrm{Ca}_{2} \mathrm{AlFeO}_{5}$ adalah salah satu dari empat fasa utama bahan baku semen seperti Portland klinker. Selain itu aplikasi yang lain untuk pemanfaatan senyawa juga telah diteliti seperti aplikasi di bidang elektronik, fotokatalis, bahkan untuk pengembangan bahan penyerap gelombang elektromagnetik di bidang telekomunikasi [3$6]$.

Sintesis bahan brownmillerite berbasis $\mathrm{Ca}_{2} \mathrm{Fe}_{2} \mathrm{O}_{5}$ pada penelitian ini diarahkan kepada pemanfaatan sebagai penyerap gelombang elektromagnetik. Salah satu syarat bahan penyerap gelombang elektromagnetik adalah memiliki permeabilitas yang tinggi [7-8]. Upaya untuk meningkatkan permeabilitas pada bahan ini dilakukan dengan pembuatan komposit dengan bahan magnetik $\mathrm{NiFe}_{2} \mathrm{O}_{4}$ [9], di mana diharapkan terjadi crosslink di antara bahan-bahan pembentuk komposit tersebut.

Pada penelitian ini dilakukan sintesis dan karakterisasi komposit smart magnetic $\mathrm{Ca}_{2} \mathrm{Fe}_{2} \mathrm{O}_{5} / \mathrm{NiFe}_{2} \mathrm{O}_{4}$ yang diharapkan dapat dijadikan sebagai bahan penyerap gelombang elektromagnetik. Jadi, tujuan penelitian ini adalah untuk mengetahui terbentuknya komposit antara $\mathrm{Ca}$ dan $\mathrm{Ni}$ melalui analisis data hasil pengukuran difraksi sinar-X, dan untuk mengetahui sifat magnetik dari komposit tersebut melalui analisis kurva histerisis hasil pengukuran menggunakan vibrating sample magnetometer.

\section{METODE PERCOBAAN}

Sintesis bahan magnet brownmillerite berbasis $\mathrm{Ca}_{2} \mathrm{Fe}_{2} \mathrm{O}_{5}$ dilakukan dengan metode reaksi padatan [9] dengan bahan baku $\mathrm{CaCO}_{3}$ (Merck) dan $\alpha-\mathrm{Fe}_{2} \mathrm{O}_{3}$ (Merck), dengan kemurnian pro analisis $(99,9 \%)$ dan sesuai komposisi stoikiometri seperti yang ditunjukan pada reaksi berikut:

$2 \mathrm{CaCO}_{3}+\mathrm{Fe}_{2} \mathrm{O}_{3} \rightarrow \mathrm{Ca}_{2} \mathrm{Fe}_{2} \mathrm{O}_{5}+2 \mathrm{CO}_{2}$

Hal yang sama dilakukan untuk sintesis komposit magnetik $\mathrm{Ca}_{2} \mathrm{Fe}_{2} \mathrm{O}_{5} / \mathrm{NiFe}_{2} \mathrm{O}_{4}$ dengan penambahan bahan baku $\mathrm{NiO}$ (Merck) dengan kemurnian pro analisis juga. Bahan-bahan tersebut dicampur dengan menggunakan high energy milling selama 5 jam. Campuran hasil proses milling dibuat sampel pelet dengan tekanan kompaksi 5000 psi, yang kemudian disintering pada suhu $1000^{\circ} \mathrm{C}$ selama 5 jam dan didinginkan di dalam furnace.

Analisis kualitas dan kuantitas fasa-fasa yang ada di dalam sampel diukur dengan menggunakan alat $X$-ray diffractometer (XRD) Pan Analytical. Pengukuran pola difraksi sampel dilakukan dengan berkas sinar-X dari tube anode $\mathrm{Cu}$ (copper) dengan panjang gelombang, $\lambda=1,5406 \AA$, mode: continuousscan, step size $0,05^{\circ}$, dan time per step 0,5 detik. Profil difraksi sinar-X dianalisis dengan menggunakan perangkat lunak GSAS (General Strucutre Analysis System) [10]. Analisis struktur mikro menggunakan SEM (scanning electron microscope), sedangkan analisis sifat magnet menggunakan VSM (vibrating sample magnetometer).

\section{HASIL DAN PEMBAHASAN}

Brownmillerite berbasis $\mathrm{Ca}_{2} \mathrm{Fe}_{2} \mathrm{O}_{5}$ disintesis melalui metode reaksi padatan dengan menggunakan mechanical milling dengan bahan baku $\mathrm{CaCO}_{3}, \alpha-\mathrm{Fe}_{2} \mathrm{O}_{3}$, dan etanol. Pada Gambar 1 diperlihatkan hasil refinement dengan menggunakan program GSAS (General Strucutre Analysis System) untuk pola difraksi sinar-X sampel brownmillerite berbasis $\mathrm{Ca}_{2} \mathrm{Fe}_{2} \mathrm{O}_{5}$. 


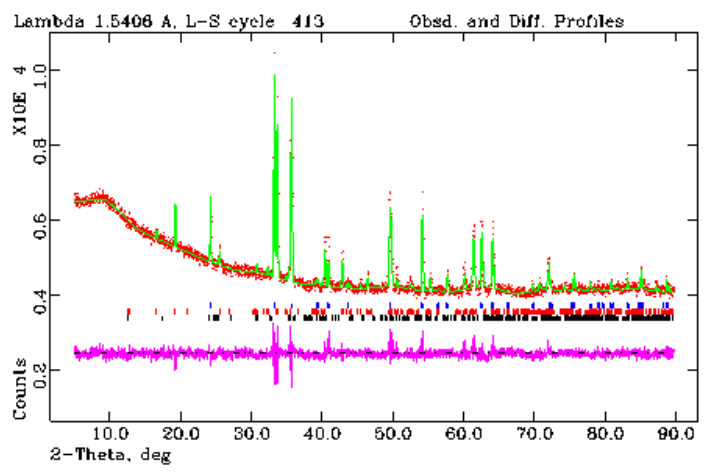

Gambar 1. Refinement Pola Difraksi Sinar-X Sampel Brownmillerite Berbasis $\mathrm{Ca}_{2} \mathrm{Fe}_{2} \mathrm{O}_{5}$
Identifikasi fasa ini dilakukan dengan cara mencocokkan data hasil pengukuran difraksi sinar-X dengan database yang terdapat di dalam program Match. Hasil dari identifikasi fasa untuk sampel ini terdiri dari tiga fasa, yaitu fasa $\mathrm{Ca}_{2} \mathrm{Fe}_{2} \mathrm{O}_{5}$ dengan nomor kartu 96901-6014, fasa $\mathrm{CaFe}_{2} \mathrm{O}_{4}$ dengan nomor kartu 96-100-9037, dan fasa $\mathrm{Fe}_{2} \mathrm{O}_{3}$ dengan nomor kartu 96-901-5965.

Pada Gambar 1 tampak bahwa fasa brownmillerite berbasis $\mathrm{Ca}_{2} \mathrm{Fe}_{2} \mathrm{O}_{5}$ telah terbentuk dengan fraksi massa yang ditunjukkan pada Tabel 1.

Tabel 1. Parameter Struktur, Criteria (Factor R), Goodness of Fit (S), dan Fraksi Massa

\begin{tabular}{|c|c|}
\hline Fasa $\mathrm{Ca}_{2} \mathrm{Fe}_{2} \mathrm{O}_{5}$ & \\
\hline $\begin{array}{l}\text { Grup ruang (space group) : P n m a, Sistem kristal : Ortorombik } \\
\text { Parameter kisi }: a=5.068(5) \AA, b=13.95(1) \AA \text { dan } c=5.458(5) \AA \text {, } \\
\alpha=\beta=\gamma=90^{\circ}, \mathrm{V}=386.0(4) \AA^{3} \text { dan } \rho=4.678 \text { gr.cm }^{-3}\end{array}$ & $88,38 \%$ \\
\hline \multicolumn{2}{|l|}{ Fasa $\mathrm{CaFe}_{2} \mathrm{O}_{4}$} \\
\hline $\begin{array}{l}\text { Grup ruang (space group) : P b n m, Sistem kristal : } \\
\text { Ortorombik Parameter kisi : } a=10.685(7) \AA, b=9.210(5) \AA \\
\text { dan } c=3.015(1) \AA \text {, } \\
\alpha=\beta=\gamma=90^{\mathrm{O}}, \mathrm{V}=296.8(2) \AA^{3} \text { dan } \rho=4.828 \text { gr.cm }^{-3}\end{array}$ & $9,03 \%$ \\
\hline \multicolumn{2}{|l|}{ Fasa $\mathrm{Fe}_{2} \mathrm{O}_{3}$} \\
\hline $\begin{array}{l}\text { Grup ruang (space group) : R -3 c, Sistem kristal : Heksagonal } \\
\text { Parameter kisi }: a=b=5.028(1) \AA \text { dan } c=13.726(5) \AA, \\
\alpha=\beta=90^{\circ} \text { dan } \gamma=120^{\circ}, \mathrm{V}=300.5(1) \AA^{3} \text { dan } \rho=5.294 \text { gr.cm }^{-3}\end{array}$ & $2,59 \%$ \\
\hline$w \mathrm{Rp}=2,14$ & 1,155 \\
\hline
\end{tabular}

Pembentukan fasa $\mathrm{Ca}_{2} \mathrm{Fe}_{2} \mathrm{O}_{5}$ dalam penelitian ini memiliki fraksi massa sebesar $88,38 \%$, yang artinya bahwa sintesis sampel $\mathrm{Ca}_{2} \mathrm{Fe}_{2} \mathrm{O}_{5}$ sudah berhasil dilakukan walaupun belum sempurna.

Berdasarkan hasil penelitian ini akan dilakukan pembuatan komposit $\mathrm{Ca}_{2} \mathrm{Fe}_{2} \mathrm{O}_{5} /$ $\mathrm{NiFe}_{2} \mathrm{O}_{4}$. Komposit $\mathrm{Ca}_{2} \mathrm{Fe}_{2} \mathrm{O}_{5} / \mathrm{NiFe}_{2} \mathrm{O}_{4}$ juga disintesis melalui metode reaksi padatan menggunakan mechanical milling dengan bahan baku $\mathrm{CaCO} 3, \alpha-\mathrm{Fe}_{2} \mathrm{O}_{3}$, $\mathrm{NiO}$ dan etanol. Pada Gambar 4 diperlihatkan hasil analisis struktur kristal berupa hasil refinement fitting dari pola difraksi sinar-X untuk sampel komposit $\mathrm{Ca}_{2} \mathrm{Fe}_{2} \mathrm{O}_{5} / \mathrm{NiFe}_{2} \mathrm{O}_{4}$.
Pada Gambar 2 tersebut juga ditunjukkan bahwa telah terbentuk puncak- puncak difraksi bragg yang terdiri dari tiga fasa, yaitu fasa $\mathrm{Ca}_{2} \mathrm{Fe}_{2} \mathrm{O}_{5}$ dengan nomor kartu 96-901-6014, fasa $\mathrm{NiFe}_{2} \mathrm{O}_{4}$ dengan nomor kartu 96-901-0940, dan fasa $\mathrm{NiO}$ dengan nomor kartu 96-4329324, dengan fraksi massa seperti yang ditunjukkan pada Tabel 2. 


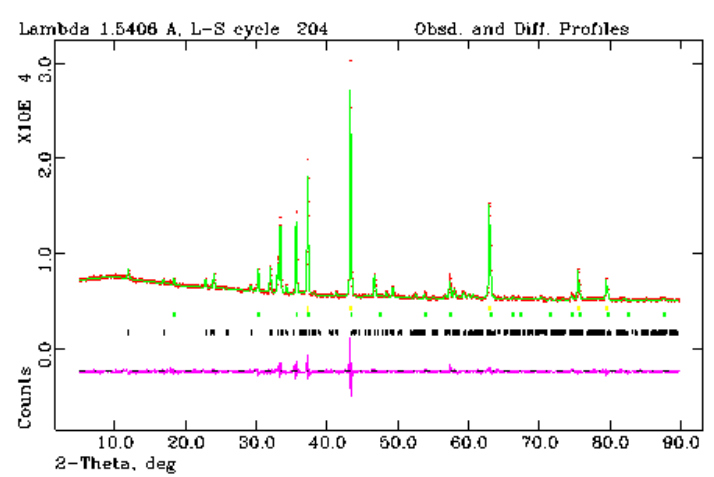

Gambar 2. Refinement Pola Difraksi Sinar-X Sampel Komposit $\mathrm{Ca}_{2} \mathrm{Fe}_{2} \mathrm{O}_{5} / \mathrm{NiFe}_{2} \mathrm{O}_{4}$
Berdasarkan hasil refinement pola difraksi sinar-X pada Gambar 2 dan Tabel 2, tampak bahwa sampel merupakan komposit $\mathrm{Ca}_{2} \mathrm{Fe}_{2} \mathrm{O}_{5} / \mathrm{NiFe}_{2} \mathrm{O}_{4}$ dengan fraksi massa antara keduanya $57,14 \%$ dan 39,27\%.

Morfologi komposit $\mathrm{Ca}_{2} \mathrm{Fe}_{2} \mathrm{O}_{5} / \mathrm{NiFe}_{2} \mathrm{O}_{4}$ diperlihatkan pada Gambar 3. Tampak ada dua bentuk partikel. Hal ini berarti bahwa sampel mengandung fasa yang berbeda (komposit), yang mendukung hasil analisis pola difraksi sinar-X

Tabel 2. Parameter Struktur, Criteria (Factor R), Goodness of Fit (S), dan Fraksi Massa

\begin{tabular}{|c|c|}
\hline Fasa $\mathrm{Ca}_{2} \mathrm{Fe}_{2} \mathrm{O}_{5}$ & \\
\hline $\begin{array}{l}\text { Grup ruang ( space group) : P n m a, Sistem kristal : Ortorombik Parameter } \\
\text { kisi : } a=5.407(4) \AA, b=14.77(1) \AA \text { dan } c=5.580(5) \AA \text {, } \\
\alpha=\beta=\gamma=90^{\circ}, \mathrm{V}=445.6(1) \AA^{3} \text { dan } \rho=4.051 \mathrm{gr.cm}^{-3}\end{array}$ & $57,14 \%$ \\
\hline Fasa $\mathrm{NiFe}_{2} \mathrm{O}_{4}$ & \\
\hline $\begin{array}{l}\text { Grup ruang (space group) : F d -3 m, Sistem kristal : Kubik Parameter kisi : } \\
\mathrm{a}=\mathrm{b}=\mathrm{c}=8.3339(4) \AA \text {, } \\
\alpha=\beta=\gamma=90^{\circ}, \mathrm{V}=578.8(1) \AA^{3} \text { dan } \rho=5.314{\mathrm{gr} . \mathrm{cm}^{-3}}^{-3}\end{array}$ & $39,27 \%$ \\
\hline Fasa $\mathrm{NiO}$ & \\
\hline $\begin{array}{l}\text { Grup ruang (space group) : F m -3 m, Sistem kristal : Kubik } \\
\text { Parameter kisi }: a=b=c=4.1793(9) \AA \text {, } \\
\alpha=\beta=\gamma=90^{\circ}, \mathrm{V}=72.99(5) \AA^{3} \text { dan } \rho=6.797 \mathrm{gr.cm}^{-3}\end{array}$ & $3,59 \%$ \\
\hline$\chi^{2}($ chi-squared $)=1$, & \\
\hline
\end{tabular}




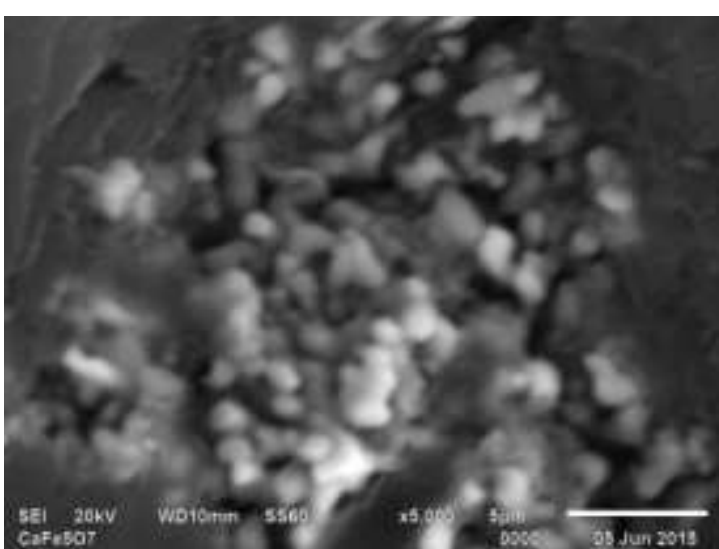

(a) Perbesaran 5.000 kali

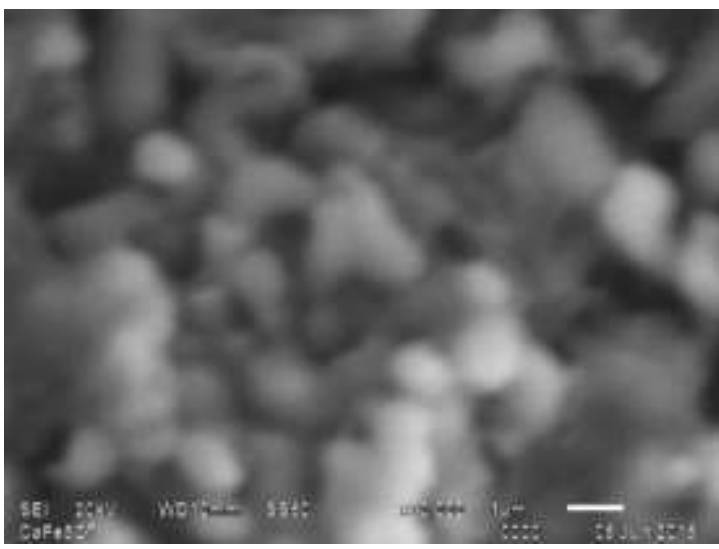

(b) Perbesaran 10.000 kali

Gambar 3.(a) dan (b) Morfologi Permukaan Sampel Komposit $\mathrm{Ca}_{2} \mathrm{Fe}_{2} \mathrm{O}_{5} / \mathrm{NiFe}_{2} \mathrm{O}_{4}$

Pada Gambar 4 ditunjukkan perbandingan hasil pengukuran sifat magnetik sampel $\mathrm{Ca}_{2} \mathrm{Fe}_{2} \mathrm{O}_{5}$ dan sampel komposit $\mathrm{Ca}_{2} \mathrm{Fe}_{2} \mathrm{O}_{5} / \mathrm{NiFe}_{2} \mathrm{O}_{4}$ dengan menggunakan vibrating sample magnetometer (VSM).

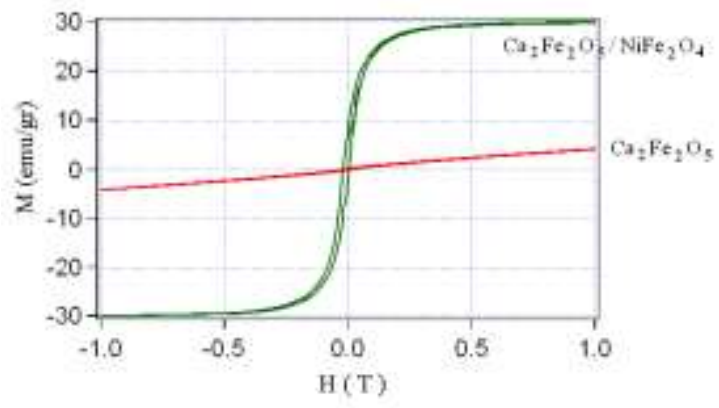

Gambar 4. Kurva Histerisis Sampel Komposit $\mathrm{Ca}_{2} \mathrm{Fe}_{2} \mathrm{O}_{5} / \mathrm{NiFe}_{2} \mathrm{O}_{4}$

Berdasarkan kurva histerisis pada Gambar 4 tampak bahwa telah terjadi perubahan sifat magnetik sampel. Jadi, sifat komposit $\mathrm{Ca}_{2} \mathrm{Fe}_{2} \mathrm{O}_{5} / \mathrm{NiFe}_{2} \mathrm{O}_{4}$ sudah menjadi feromagnetik dengan medan korsivitas Hc sebesar 150 Oe, magnetisasi rimanensi sebesar $10 \mathrm{emu} / \mathrm{gr}$, dan magnetisasi saturasi sebesar 30 emu/gr. Kontribusi sifat feromagnetik pada komposit $\mathrm{Ca}_{2} \mathrm{Fe}_{2} \mathrm{O}_{5} / \mathrm{NiFe}_{2} \mathrm{O}_{4}$ adalah hadirnya fasa nikel ferit $\left(\mathrm{NiFe}_{2} \mathrm{O}_{4}\right)$ yang memiliki sifat feromagnetik pada suhu kamar dan $\mathrm{NiFe}_{2} \mathrm{O}_{4}$ yang dikenal sebagai bahan soft magnetic dengan medan korsivitas Hc sebesar 150 Oe, magnetisasi rimanensi sebesar $10 \mathrm{emu} / \mathrm{gr}$, dan magnetisasi saturasi sebesar $30 \mathrm{emu} / \mathrm{gr}$. Hal ini berarti bahwa penelitian ini telah berhasil dilakukan sesuai dengan hipotesis.

\section{KESIMPULAN}

Sintesis dan karakterisasi komposit smart magnetic berbasis brownmillerite $\mathrm{Ca}_{2} \mathrm{Fe}_{2} \mathrm{O}_{5} / \mathrm{NiFe}_{2} \mathrm{O}_{4}$ telah berhasil dilakukan. Berdasarkan hasil refinement pola difraksi sinar-X, ditemukan bahwa sampel merupakan komposit $\mathrm{Ca}_{2} \mathrm{Fe}_{2} \mathrm{O}_{5} / \mathrm{NiFe}_{2} \mathrm{O}_{4}$ dengan fraksi massa antara keduanya $57,14 \%$ dan $39,27 \%$. Hal ini didukung juga oleh hasil morfologi permukaan yang menunjukkan bahwa sampel terdiri dari pola bentuk partikel yang berbeda. Berdasarkan hasil analisis sifat magnetik, sampel komposit $\mathrm{Ca}_{2} \mathrm{Fe}_{2} \mathrm{O}_{5} / \mathrm{NiFe}_{2} \mathrm{O}_{4}$ bersifat feromagnetik.

\section{DAFTAR PUSTAKA}

1. Asenath-Smith, E., I. N. Lokuhewa, S.T. Misture and D. D. Edwards: p-Type Thermoelectric Properties of the OxygenDeficient Perovskite $\mathrm{Ca}_{2} \mathrm{Fe}_{2} \mathrm{O}_{5}$ in the Brownmillerite Structure. Journal of Solid State Chemistry 183 (2010) Issue 7, pp. 1670-1677.

2. Asenath-Smith, E., S. T. Misture and D. D. Edwards: Structural Behavior and Thermoelectric Properties of the Brownmillerite System $\mathrm{Ca}_{2}\left(\mathrm{Zn}_{\mathrm{x}} \mathrm{Fe}_{2-\mathrm{x}}\right) \mathrm{O}_{5}$, Journal of Solid State Chemistry 184, (2011), Issue 8, pp. 2167-2177

3. Matsuki, Malik A Bagiya, dan Darminto, Sintesis dan Karakterisasi Kalsium Ferit Menggunakan Pasir Besi dan Batu Kapur, Jurnal Sains dan Seni ITS Vol.1, No.1, September 2012, ISSN : 2301-928X

4. Friged Harianto dan Darminto, Sintesis Kalsium Ferit Berbahan Dasar Pasir Besi dan Batu Kapur dengan Metode Reaksi 
Padatan, Jurnal Sains dan Seni Vol., No,1, Januari 2013, ISSN:2301-928X

5. Bao-jin Xue, Jia Luo, Fan Zhang, Zhen Fang, Biodiesel production from soybean and Jatropha oil by magnetic $\mathrm{CaFe}_{2} \mathrm{O}_{4}$ $\mathrm{Ca}_{2} \mathrm{Fe}_{2} \mathrm{O}_{5}$-based catalyst, Journal Elsevier, Energy 68, 2014, 584-591

6. Željka Kesić , Ivana Lukić , Miodrag Zdujić, Čedomir Jovalekić, Vlada Veljković, Dejan Skala, Assessment of $\mathrm{CaTiO}_{3}, \mathrm{CaMnO}_{3}, \mathrm{CaZrO}_{3}$ and $\mathrm{Ca}_{2} \mathrm{Fe}_{2} \mathrm{O}_{5}$ perovskites as heterogeneous base catalysts for biodiesel synthesis, Fuel Processing Technology, 143 (2016) 162168.

7. Sameer Dugga, Gagan Deep Au, Review on Effect of Electric Permittivity and Magnetic Permeability over Microwave Absorbing Materials at Low Frequencies, International Journal of Engineering and Advanced Technology, Volume-3, Issue-5, June 2014, 12-19.
8. Wisnu Ari Adi and Azwar Manaf, Microstructure and Phase Analysis of $\mathrm{La}_{0.8} \mathrm{Ba}_{0.2} \mathrm{Ti}_{\mathrm{x}} \mathrm{Mn}_{(1-\mathrm{x})} \mathrm{O}_{3}$ system for Microwave Absorber Material ( $\mathrm{x}=0-$ 0.7), Advanced Materials Research Vol. 789 (2013) pp 97-100.

9. Sunny, V., Kurian, P., Mohanan, P., Joy, P. A., and Anantharaman, M. R., "A flexible microwave absorber based on nickel ferrite nanocomposite," J. Alloys Compd. 489, pp. 297-303, 2010.

10. Toby, B.H., EXPGUI, A graphical user interface for GSAS, Journal of Applied Crystallography, 34, 210. 2001.

11. Cléber Candido da Silva, Antonio S. B. Sombra, Temperature Dependence of the Magnetic and Electric Properties of $\mathrm{Ca}_{2} \mathrm{Fe}_{2} \mathrm{O}_{5}, \quad$ Materials Sciences and Applications, 2011, 2, 1349-1353. 